\title{
Variability of Spatially Grid-Distributed Precipitation over the Huaihe River Basin in China
}

\author{
Zhi-Lei Yu ${ }^{1,2,3}$, Deng-Hua Yan ${ }^{2,3, *}$, Guang-Heng Ni ${ }^{1}$, Pierre Do ${ }^{1}$ (D), Deng-Ming Yan ${ }^{2,3,4}$, \\ Si-Yu Cai ${ }^{1,2,3}$, Tian-Ling Qin ${ }^{2,3}$, Bai-Sha Weng ${ }^{2,3}$ and Mei-Jian Yang 5 \\ 1 Department of Hydraulic Engineering, Tsinghua University (THU), Beijing 100084, China; \\ yzl16@mails.tsinghua.edu.cn (Z.-L.Y.); ghni@tsinghua.edu.cn (G.-H.N.); \\ dodmp10@mails.tsinghua.edu.cn (P.D.); caisy@iwhr.com (S.-Y.C.) \\ 2 State Key Laboratory of Simulation and Regulation of Water Cycle in River Basin, China Institute of Water \\ Resources and Hydropower Research (IWHR), Beijing 100038, China; 18655058842@163.com (D.-M.Y.); \\ tianling406@126.com (T.-L.Q.); baishaweng@126.com (B.-S.W.) \\ 3 Department of Water Resources, IWHR, Beijing 100038, China \\ 4 College of Environmental Science and Engineering, Donghua University, Shanghai 201620, China \\ 5 Department of Civil and Environmental Engineering, University of Connecticut, Storrs, CT 06269, USA; \\ meijian.yang@uconn.edu \\ * Correspondence: yandh1006@sina.com; Tel.: +86-10-6878-1656
}

Received: 8 March 2017; Accepted: 22 June 2017; Published: 5 July 2017

\begin{abstract}
This study investigates spatial characteristics of annual and decadal precipitation in the Huaihe River basin. Daily precipitation data, obtained from meteorological gauges, are analyzed for a 51-year period, from 1961 to 2011. Precipitation is analyzed in grids $\left(5 \mathrm{~km}^{2}\right)$ with respect to temporal variability. The spatial distribution and intensity of annual rainfall $(\mathrm{mm} / 10$ year), determined by the linear regression method, reveals a slight increase of $3 \mathrm{~mm} / 10$ year over the basin. However, the trend did not present a significant change at $95 \%$ significance level in the most of basin. Precipitation is mostly increasing for each ten-year periods during the total 51 years. The annual precipitation randomicity was calculated from the non-uniform coefficient $C v$ (coefficient of variation) test and showed a significant non-uniform spatial distribution, indicating that randomicity of annual rainfall was the moderate variability. The Pettitt test determined that the abrupt change points occurred mainly in 1965, 1975 and 2002. Wavelet analysis showed that cyclic variations appeared almost every 5 to 10 years, accounting for $36 \%$ of the basin area. Meanwhile, these cycles tended to be delimited by the abrupt change points. This study aims to provide insights for water resources management, mitigation of climate change effects and water supply in the Huaihe River basin and surrounding watersheds.
\end{abstract}

Keywords: wtershed hydrology; grid-distributed precipitation; Huaihe River basin; linear regression method; coefficient of variation; Pettitt test; wavelet analysis

\section{Introduction}

Precipitation is the essential feature of the climate change and a key element of the hydrological processes $[1,2]$. Change in precipitation has greatly affected climate stability, hydrological processes, and water availability $[3,4]$. The spatial and temporal distribution changes of precipitation affect the frequent occurrence of extreme events, especially droughts and floods [4,5]. Therefore, exploring the characteristic changes of precipitation is of profound significance. It is essential for agricultural production, the planning and management of sustainable water resources, and overall economic development and livelihood of a country [6-8]. 
Many authors have documented the spatial and temporal variation characteristics of the precipitation throughout the world [9-12]. For example, scholars described precipitation trends in Nigeria using the monthly accumulations of precipitation for period 1961-2000 [2]. They observed that the spatial distribution of precipitation highly depended on the latitude and its linear relationship with longitude was not clear. Tabati and Talaee found a decreasing trend in annual precipitation in most of the 41 stations they observed in Iran from 1966 to 2005 [13]. Tian analyzed the variation characteristics of precipitation in the main rivers of China during 1957-2013 [14]. Their results showed the annual precipitation and seasonal mean precipitation changed little. Scholars described the spatio-temporal variations of the frequency of extreme precipitation using a high quality precipitation dataset of 599 stations in China for 1961-2001 [15]. Liu studied the spatio-temporal patterns of trends of the precipitation in the Yellow River basin during 1960-2006 and indicated that the precipitation possessed longitude zonality and had no obvious linear relations with the latitude [16]. Another scholar simulated the precipitation change over the past 50 years and the next 30 years in various regions of China, and the research results showed a clear warm-in trend [17].

Most previous studies were focused on the temporal scales, such as interannual [8], interdecadal [1], decadal [9], annual [18], seasonal [6,7], monthly [3], daily [19,20], and even finer temporal scales [21]. However, few investigations have been conducted on continuous spatial distribution of rainfall on a basin scale [16] and in particular the spatial variability [22]. Most studies emphasized discrete variations in the study area $[6,23]$. The annual precipitation describes a high spatial and temporal variability [24].

The spatial characteristics of precipitation was the major control factor of rainfall-runoff simulation and a series of other hydrological problems [25]. The uncertainty of flood forecasting mainly derived from the rainfall uncertainty and the most sensitive factor of flood peaks prediction was the spatial variation of rainfall [26]. We can obtain the precise spatial distribution of rainfall by establishing rainfall or meteorological stations with extremely high density. Although there are a lots of meteorological and rainfall stations in China, the limited observation data and scientific literature cannot meet the needs of the distributed hydrological model. Precipitation is not uniform and its change is considerably in space and time, including small scales, therefore, it is particularly hard to gauge these changes [27]. We need to extrapolate the data to spatial grids across the watershed to compensate for the unevenly distributed of meteorological stations.

In previous studies, due to the lack of scientific literature to document the spatial and temporal extent of precipitation across the basin or watershed, most researches used single point data to obtain the rain changes in different basins. Based on single point data, our study primarily extrapolated the data across the watershed and extended the findings by quantitatively analyzing the spatial variability of annual and decadal rainfall in the Huaihe River basin for a long-term period (from 1961 to 2011). This investigation used data from 45 meteorological stations distributed over the study area (Figure 1). This research aims to provide basic climate information for river basin management. 


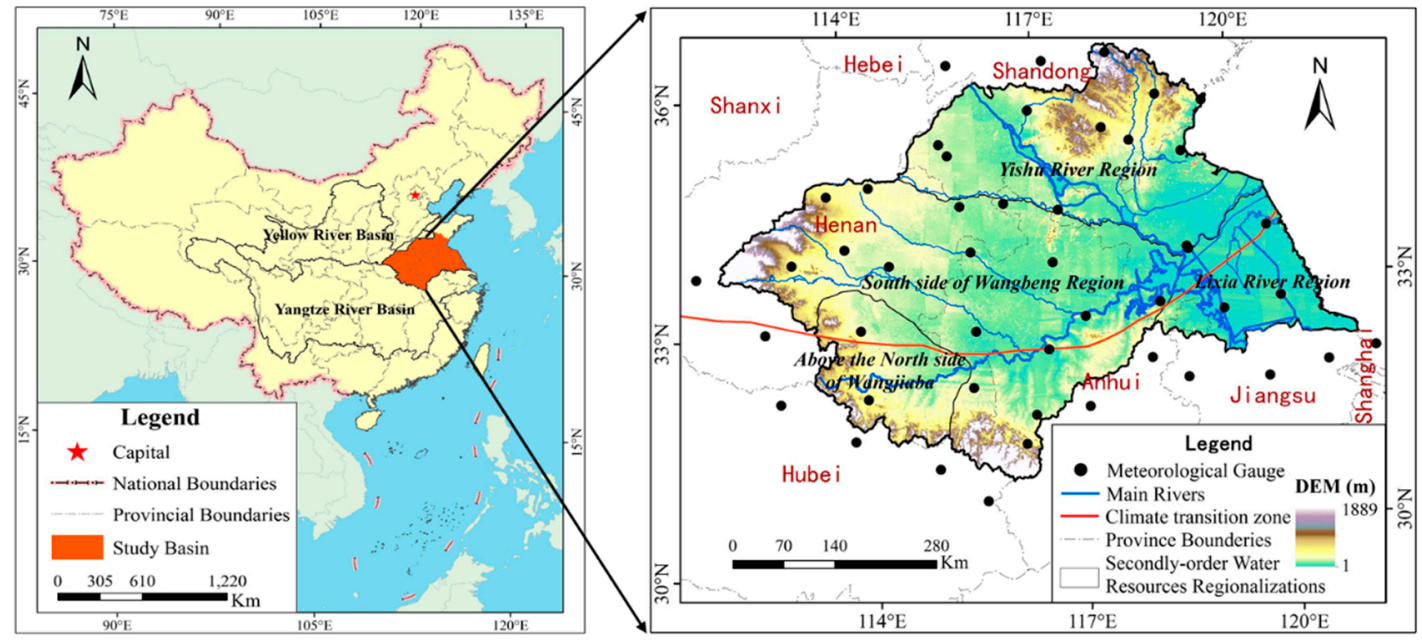

Figure 1. The inset map displays the location of the Huaihe River basin (red shading) in China. The main map shows the location of the Huaihe River basin where the bold black line reveals the boundary of the Huaihe River. The location of the meteorological stations showed by the black circle.

\section{Data and Methods}

\subsection{Study Area}

The study area is the whole Huaihe River basin, which lies approximately between $30^{\circ} 57^{\prime} \mathrm{N}-36^{\circ} \mathrm{N}$ and $112^{\circ} \mathrm{E}-121^{\circ} \mathrm{E}$ in eastern China (see Figure 1). It lies in the region from the Yangtze River basin in the south to the Yellow River basin in the north. The total geographical area of the basin is approximately $259,700 \mathrm{~km}^{2}$. The whole basin is divided into the Huaihe River catchment and the Yishusi River catchment by the paleo-channel of the Yellow River and is composed of four secondly-order water resource regionalizations. Its landscape is characterized by the near level plain and hill, among which the plain occupies more than $80 \%$ of the total basin area. The spatio-temporal distribution of annual precipitation is uneven in the basin. The mean annual precipitation in the Huaihe River basin during 1961 to 2011 is $884 \mathrm{~mm}$. While the average annual maximum precipitation is 2.5 times bigger than the minimum for the period of 1961 to 2011, and the precipitation amount notably decreases from southeast to northwest. Mean annual temperature is approximately $14.47^{\circ} \mathrm{C}$, and average maximum temperature goes up to $15.79^{\circ} \mathrm{C}$, whereas the minimum temperature drops to $7.38^{\circ} \mathrm{C}$ for period from 1961 to 2011 . With the dramatic effects of the global climate changes and human activities, underlying surfaces and water resources changes of the Huaihe River basin have attracted more and more attention. In addition to its special geographical conditions from sub-tropical zone to warm temperate zone and from wet zone to semi-arid and arid zone and complex the climate factors, the Huaihe River basin is characterized by frequent or continuous drought or flood events, floods in the south region, and droughts in the north, and drought-flood shifting [28-30].

\subsection{Data}

Based on Thiesssen polygon [31], $24 \mathrm{~h}$ observed precipitation data were collected from 45 meteorological stations during the 1961 to 2011 period. These information are available in the National Meteorological Information Centre (NMIC) online database provided by the China Meteorological Administration [32]. For each meteorological station, discrete daily precipitation data were converted into $5 \mathrm{~km}^{2}$ grid-distributed yearly precipitation. This interpolation used the Arc-GIS framework by inverse-distance-weighted (IDW) method. Each grid was considered as the basic dataset used to analyze the precipitation characteristics for the 1961 to 2011 period in the Huaihe River basin. Yang revealed the trend, the abrupt change, the periodicity, and the randomicity of precipitation 
time series for the main flood period in the Huaihe River [33]. Hence, we studied the long-term (from 1961 to 2011) spatial variability of annual and decadal precipitation in the Huaihe River basin using statistical methods through four aspects: the trend, the abrupt change, the periodicity, and the randomicity.

\subsection{Methods}

We use the Matlab R2012b to calculate the precipitation abrupt change and periodicity, and the ArcGis 10.2 to obtain the rainfall trend and randomicity. The ArcGis 10.2 is also used to generate the rainfall characteristics spatial interpolation maps. The study performed the spatial trend analysis of precipitation in the Huaihe River basin over the period of 1961 to 2011 using the linear regression method. The randomicity of precipitation changes was detected by the coefficient of variation $(\mathrm{Cv})$ and abrupt change points of observed precipitation data were caught by the Pettitt test. The wavelet analysis determined the precipitation period. Then the spatial distribution of annual and decadal precipitation were obtained. The statistical test and methods used in this study are described below:

\subsubsection{Linear Regression Method}

The linear regression method is employed to investigate and analyze the long-term trends of precipitation in the time series. The main statistical parameter, the slope, is used to indicate the temporal change of the studied variable on the spatial scale. This method intuitively reflects the trend of the rainfall time series, and the slope of the linear equation represents the average change rate of the trend (to define the slope $\times 10$ as the precipitation tendency rate; unit: $\mathrm{mm} /$ decade) [34]. The following formula is proposed by Li to computer the slope [35]:

$$
\text { Slope }=\frac{n \times \sum_{i=1}^{n}\left(i \times P_{i}\right)-\sum_{i=1}^{n} i \sum_{i=1}^{n} P_{i}}{n \times \sum_{i=1}^{n} i^{2}-\left(\sum_{i=1}^{n} i\right)^{2}}
$$

where slope represents the estimated linear trend of precipitation during the period of 1961 to 2011. Positive values of the slope indicate increasing trends, while negative values of the slope denote decreasing trends [13]; $i$ is the number of years in the time series (this study is from 1 to 51 ); and $P_{i}$ is the annual precipitation amount. We used the MK test to detect whether a trend in the rainfall time series is statistically significant at a $95 \%$ confidence level [14].

\subsubsection{Coefficients of Variation}

The coefficient of variation $(\mathrm{Cv})$ is a unit-free and effective normalized measure of dispersion [36]. Some scholars used the non-uniform coefficient $C v$ to quantify the evenness of monthly precipitation [15]. Where rainfall is more uneven, the randomicity is much greater. We applied the $C v$ for detecting and analyzing the randomicity of annual and decadal precipitation. In this study, $C v$ was estimated with the standard deviation and mean values [37-40]. It can be expressed as:

$$
C v=\sqrt{\frac{\sum_{i=1}^{n}\left(K_{i}-1\right)^{2}}{n-1}}, \text { and } K_{i}=\frac{P_{i}}{\bar{P}},
$$

where $C v$ is the randomicity of precipitation amount, namely the discreteness of precipitation. The larger the $C v$ value is, the greater the randomicity of precipitation changes is considered to be. In other words, the $C v$ is high, which indicates the uneven distribution of the annual precipitation in the basin [41]. The $K_{i}$ is the coefficient of modulus. When the $C v$ is greater than 1 , the randomicity of precipitation is defined as the strong variability; $0.1 \leq C v \leq 1$ means the moderate variability; $C v$ less than 0.1 means the weak variability [42]. 


\subsubsection{Pettitt Test}

The non-parametric Pettitt statistical test is frequently applied to explore the abrupt change point in a long-term trend analysis [43]. The Pettitt test can not only judge the location and number of the abrupt change, but also estimate the significance of the abrupt change $[18,44]$. The Pettitt test is considered as a powerful and useful method for obtaining the abrupt change points in characterizing the trends of climate data [23]. The test statistic $U_{t, n}$ is given by:

$$
U_{t, n}=\sum_{i=1}^{t} \sum_{j=t+1}^{n} \operatorname{sgn}(\theta), \theta=P_{i}-P_{j}, 1 \leq t \leq n
$$

where $n$ is the time length of precipitation data set, and $P$ is the annual precipitation amount at time $i$ and $j$, and:

$$
\operatorname{sgn}(\theta)=\left\{\begin{array}{cc}
+1 & \text { for } \theta>0 \\
0 & \text { for } \theta=0 \\
-1 & \text { for } \theta<0
\end{array}\right.
$$

The most probable change point is obtained where its value is as follows:

$$
k_{t}=\max _{1 \leq t \leq n}\left|U_{t, n}\right|
$$

and the significance probability $\rho$ associated with $k_{i}$ is expressed by:

$$
\rho=2 \exp \left(\frac{-6 k_{t}^{2}}{n^{3}+n^{2}}\right)
$$

If $\rho$ is less than the specific significance level, the null hypothesis is rejected. That is, if a significant change point subsists, the time series is segregated into parts at the abrupt change point $t$. The approximate significance probability for an abrupt change point is expressed as $p=1-\rho$. In our study, the specific significance level is at $95 \%$ confidence level.

\subsubsection{Wavelet Analysis}

Wavelet analysis is a powerful method to research multi-scale, non-stationary signals in finite spatial and temporal domains [11,45-47]. It has been applied in atmospheric sciences and geophysics $[47,48]$. The Morlet wavelet is a very accurate method for obtaining the periodicity in a few similar studies but is applied little for studying the periodicity in a database $[49,50]$. Therefore, we use a continuous wavelet transform (CWT) to detect the existence of oscillations and their period [46]. The Morlet wavelet is widely used to identify periodic oscillations of the real life signals and possesses an obvious strength that allows detection of time-dependent amplitude and phase for different frequencies due to its complex nature [46,51]. The Matlab R2012b software is utilized here to seek the rainfall periodicity with the above discussed Morlet wavelet.

\section{Results}

\subsection{Spatial Variations of Annual Precipitation}

The spatial distribution of the average annual precipitation presents a multi-step increase along the northwest-southeast direction throughout the basin (Figure 2a). That is, precipitation occurs more often in the southeastern basin than in the northwest. Dry regions are located in the northwest (inland) while wet ones are in the southeast (coast). The maximum mean annual rainfall concentrates in the Dabie Mountain region (Figure 2b). 


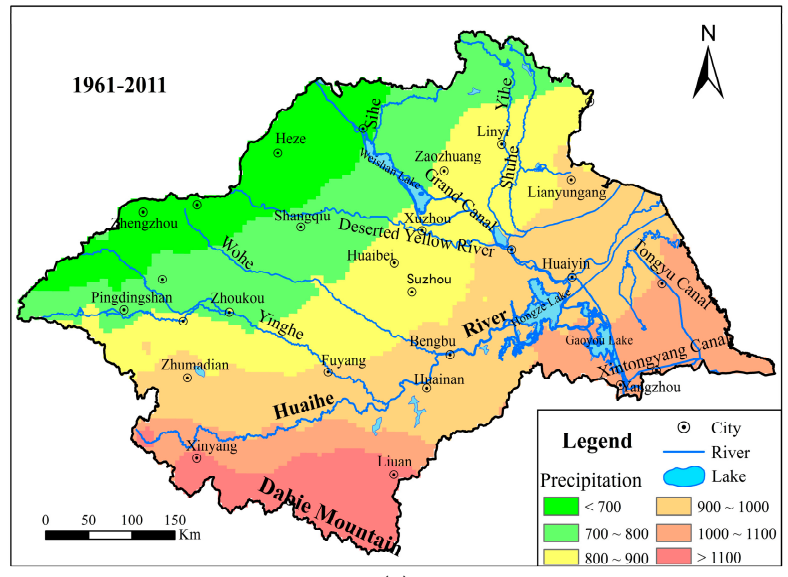

(a)

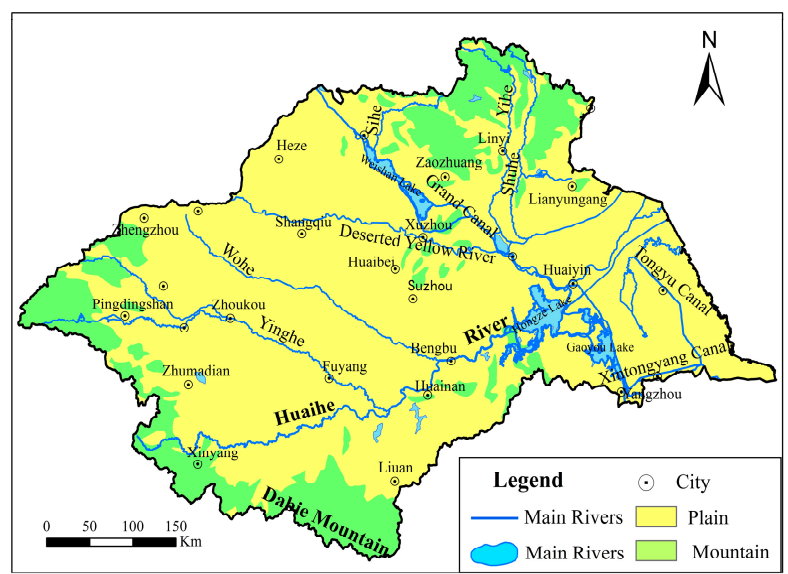

(b)

Figure 2. The spatial distribution of the average annual precipitation during 1961 to 2011 (a) and the main physiognomy (b) in the Huaihe River basin.

\subsubsection{Trends of Annual Precipitation}

Based on the grid annual rainfall, the spatial trend distribution of annual precipitation and their magnitudes ( $\mathrm{mm} /$ decade) calculated by the linear regression method are given in Figure 3a. The annual precipitation in the basin presents a slight increasing trend and its mean tendency rate is $3 \mathrm{~mm} / 10$ year.

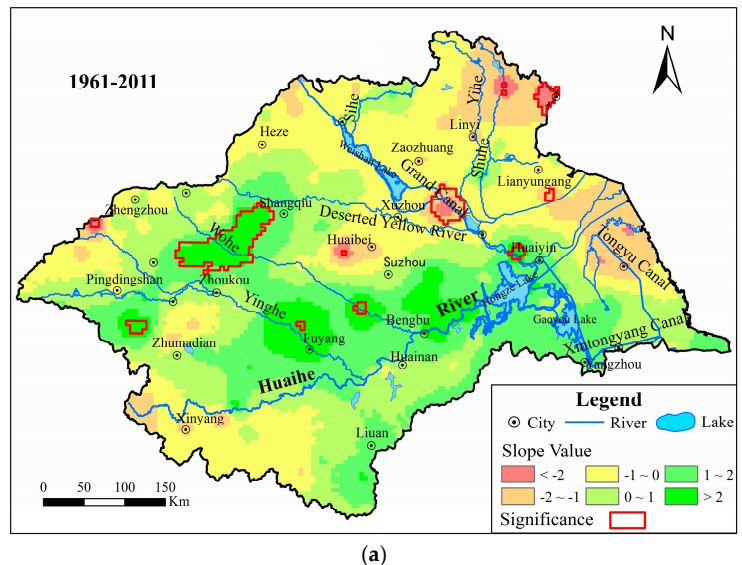

Figure 3. Cont. 

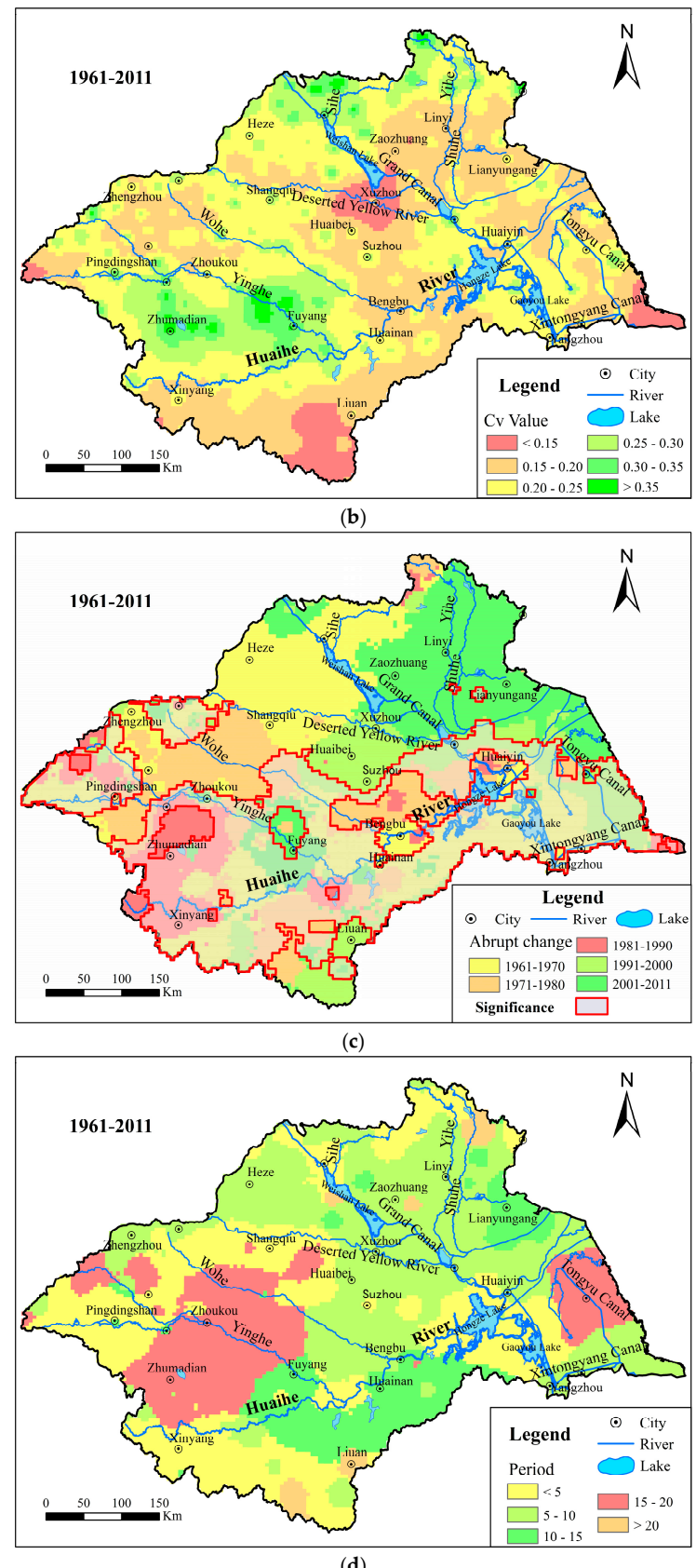

Figure 3. Spatital distribution for trend (a); randomicity (b); abrupt change (c) and periodicity (d) of annual precipitation during 1961 to 2011 in the Huaihe River basin.

About $58 \%$ of the areas had a positive trend and the rest showed a negative trend. The positive trends were found mostly in southeastern, middle, and northwestern zones along the mainstream of the Huaihe River and branches of the Guohe and Yinghe Rivers. In contrast, negative trends were discovered in Yihe and Shuhe Rivers in the northeastern region, and also in the southwest. In addition, we studied the spatial distribution of the temporal trend magnitude of annual precipitation (from 1961 to 2011) in the Huaihe River basin (Figure 3a). The positive trend magnitude varied between 0 and $40 \mathrm{~mm} / 10$ year, in general. The proportion of magnitude ranging between 0 and $10 \mathrm{~mm} / 10$ year and between 10 and $20 \mathrm{~mm} / 10$ year was approximately $27 \%$ and $28 \%$, respectively. These parts were mainly grouped in the area from the southeastern basin to the northwest. The negative trend magnitude changed was from about -40 to $0 \mathrm{~mm} / 10$ year. The range of the magnitude between 
-10 and $0 \mathrm{~mm} / 10$ year accounted for about $31 \%$ and was mostly distributed in the northeastern zones. In fewer regions (less than $10 \%$ ), the trend magnitude was greater or less than 20 or $-20 \mathrm{~mm} / 10$ year. These zones were scattered loosely all around the basin. Via the significance test, we found that the trend changes of annual rainfall were not significant in most of the basin.

\subsubsection{Randomicity of Annual Precipitation}

Based on the $C v$ test, Figure $3 \mathrm{~b}$ indicates annual precipitation had the different spatial variations between 1961 and 2011 in the Huaihe River basin. The randomicity was greater in the part of the west and north regions than in the middle and southwest. The overall range of $C v$ s changed between 0.18 and 0.31 and the randomicity of annual rainfall was determined as the moderate variability. The Cvs, ranging between 0.22 and 0.26 , were detected at the rate of $89 \%$ and distributed nearly in the whole area; the Cvs greater than 0.26 were primarily around Zhumadian and Fuyang, which accounted for about $5 \%$ of the total area analyzed. The Cvs were less than 0.22 , and its proportion of the region area was approximately $5 \%$ in the vicinity of Xuzhou, the southwest of Liuan, and the southeast corner. The Cvs were less than 0.2 in the rest of the area. The annual rainfall uneven distribution was obvious in the north, upstream of the Huaihe River and downstream of the Yihe and Sihe Rivers. The geomorphology of these regions was mainly the plain (Figure $2 b$ ). In contrast, the inhomogeneous changes of the annual precipitation were slight in the mountain regions. These implicated that the annual precipitation distribution was more heterogeneous in mountain areas than in the plain.

Across the basin, the spatial distribution of the randomicity showed uneven precipitation patterns over the last 50 years. The rainfall homogeneity was greater upstream than downstream of the Huaihe River. In particular, the $C v$ was much greater in the Shahe River and Yinghe River regions. It also showed that variability of rainfall in these regions was stronger than in other areas.

\subsubsection{Abrupt Change of Annual Precipitation}

The Pettitt test was used to obtain the abrupt change in the precipitation time series during the study period. The different abrupt points were detected in various 10-year periods (Figure 3c) and the distribution proportion of abrupt changes varied by decade. Except from 1981 to 1990, the abrupt changes nearly increased with time. The abrupt changes occurred with a probability of ca. $16 \%$ from 1961 to 1970 . The abrupt changes was almost $22 \%$ between 1971 and 1980 . The $10 \%$ abrupt change occurred in the southwestern basin during 1981-1990. About 21\% of the total region showed an abrupt change in rainfall from 1991 to 2000. Abrupt change points (more than 30\%) emerged in the north and southeast basin, and parts of the southwest and west basin during 2001-2011. In conclusion, during the 51-year period, in all abrupt change points, 1965, 1975, and 2002 were the major abrupt change points, and their proportion of distribution accounted for $21 \%, 13 \%$, and $11 \%$, respectively.

The abrupt points were distinct during the very 10-year period. The dominant abrupt point was detected in 1965 (about 70\% of the total) during 1961-1970. From 1971 to 1980, the primary abrupt changes occurred in 1975 and 1978, and accounted for 58\% of the land area during these periods. There was an obvious abrupt point in 1984 and its proportion was ca. $60 \%$ from 1981 to 1990 . The three abrupt change points between 1990 and 2000 occurred in 1991, 1995, and 1997, and accounted for ca. $78 \%$ in this duration. During the period of 2001-2011, 2001 and 2002 were the abrupt change points, accounting for $87 \%$.

The abrupt changes were found at a $95 \%$ confidence level. There were significant abrupt changes in $47.11 \%$ of the regions in the trunk stream of the Huaihe River (Figure 3c). These areas were distributed on both sides of the Huaihe River. The years 1965, 1978, 1984, 1991, 1995, 1997, 2001, and 2002 presented abrupt changes at a 95\% significance level.

\subsubsection{Periodicity of Annual Precipitation}

The periodicity variations of the annual precipitation were calculated by wavelet analysis in the basin during the 51 years. The time-frequency distributions were shown in the various spatial region 
(Figure 3d). For the annual precipitation all year round, the six scales of periodic cycle existed: $<5,5-10$, 10-15, 15-20, and 20-25 years, almost throughout the whole time sequence. As a whole, the different cyclic length of annual precipitation distributed irregularly in the basin. During the $<5$-year period (about $32 \%$ of the total area) precipitation was chiefly distributed in the north and southwestern regions of the basin. A nearly and less than 10 -year cycle (about $36 \%$ of the total area) were mainly observed in northeastern, central, and parts of the southwestern basin. Approximately $30 \%$ of the regions where there was a 10-20-year period in the southwest region were identified. More than 20 -year cycles accounted for ca. $2 \%$.

\subsection{Spatial Variations of Inter-Decadal Precipitation}

We investigated the character distribution of the precipitation on the different time scales. The precipitation trends and the $C v$ in basin were analyzed by using nonparametric tests based on the grid data of decadal rainfall.

\subsubsection{Trends of Inter-Decadal Precipitation}

There were five 10-year periods, including the 1960s, 1970s, 1980s, 1990s, and beginning of the 21st century. The inter-decadal precipitation showed a slightly increasing trend during the various periods (from the 1960s to the beginning of the 21st century). The mean magnitude of the trend was successively about $-12,-10,3,3$, and $6 \mathrm{~mm}$ /year during the various periods. The magnitude changes were different in the basin's various orientations (Figure 4). The negative trends were detected in the north of the downstream of Huaihe River and the positive ones were in the south of the upstream of Huaihe River in the 1960s (Figure 4a), where the magnitude ranged from -58 to $41 \mathrm{~mm} /$ year. Additionally, the rainfall trends decreased sharply in parts of the northeastern basin and increased slightly in the western basin during the 1970s (Figure 4 b). The tendency magnitude was between -57 and $23 \mathrm{~mm}$ /year. Furthermore, the tendency magnitude range was from -43 to $42 \mathrm{~mm} /$ year in the 1980s (Figure 4c). The majority of the northeastern basin showed an increasing trend while a decrease occurred in the parts of the southwestern basin. Conversely, the precipitation magnitude increased in most parts of the northwestern basin and decreased in the southeast of the Huaihe River in the 1990s (Figure $4 \mathrm{~d}$ ). The magnitude ranged from -48 to $57 \mathrm{~mm} /$ year. Finally, the rainfall magnitude changed from -28 to $38 \mathrm{~mm} /$ year during the beginning of the 21st century (Figure 4e). The precipitation decreased in the parts of the central and western basin and increased in most areas. It was remarkable that all trend changes had no distinguishability by the significance test.

\subsubsection{Randomicity of Inter-Decadal Precipitation}

The decadal precipitation heterogeneity was investigated by using the Cvs (Figure 5). We demonstrated that there were notable changes between the minimum and maximum $\mathrm{Cv}$. The $\mathrm{Cv}$ vaule ranged variously (from 0.07 to 0.41 ) in different decades. The difference between the minimum and maximum $C v$ was 0.34 . However, the randomicity was also the moderate variability. It ranged between 0.14 and 0.41 in 1960s (Figure 5a). The uneven precipitation was geographically concentrated in the northern edges of the basin, where the $C v$ value was greater than 0.25 . The minimum $C v$ value was 0.07 and the maximum was 0.33 in the 1970s (Figure 5b). The precipitation was relatively even across the most areas of the basin during this period. The $C v$ ranged from 0.10 to 0.37 during the $1980 \mathrm{~s}$ period (Figure 5c). The precipitation variability was obvious in the downstream of the Yinghe River, Yihe River and Sihe River. The Cv value ranged from 0.11 to 0.41 during the 1990s (Figure 5d) and 0.11 to 0.38 at the beginning of the 21st century (Figure 5e). The precipitation was uneven in the Yinghe River basin and the south parts of the middle and lower reaches of the Huaihe River in 1990s. The dissimilar precipitation was chiefly concentrated in the north parts of the Huaihe River at beginning of the 21st century.

The mean Cvs were heterogeneous and changed from 0.20 to 0.27 . The precipitation randomicity increased during the 1960s and 1970s, and then decreased in the 1980s, and increased again between 
1990s and the beginning of the 21st century. The Cv was 0.23 in the 1960 s, which indicated that precipitation was relatively even across most of the basin. The values reached $0.27,0.20,0.23$, and 0.23 in the 1970s, 1980s, 1990s, and early 21st century, respectively. Most of the uneven precipitation occurred in the north of the Huaihe River and changed with climate change.
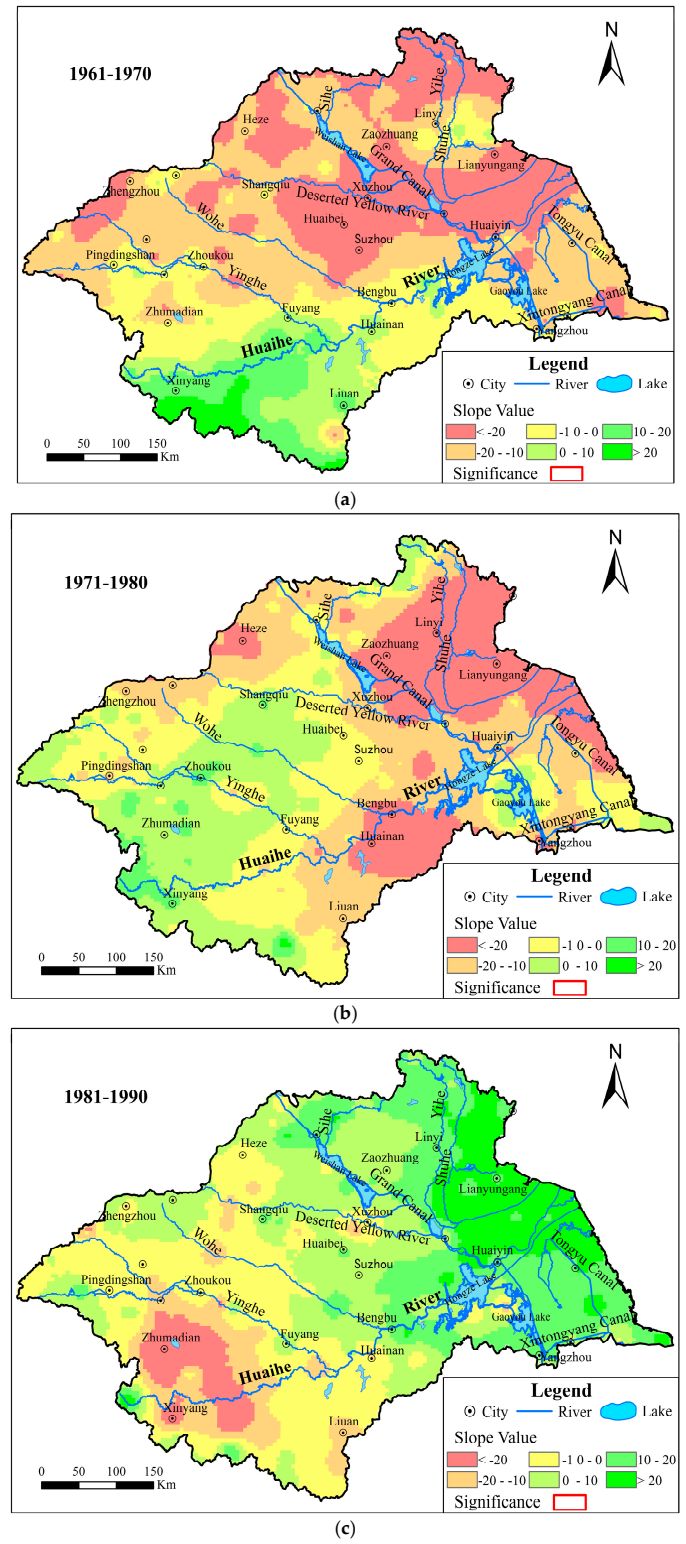

Figure 4. Cont. 

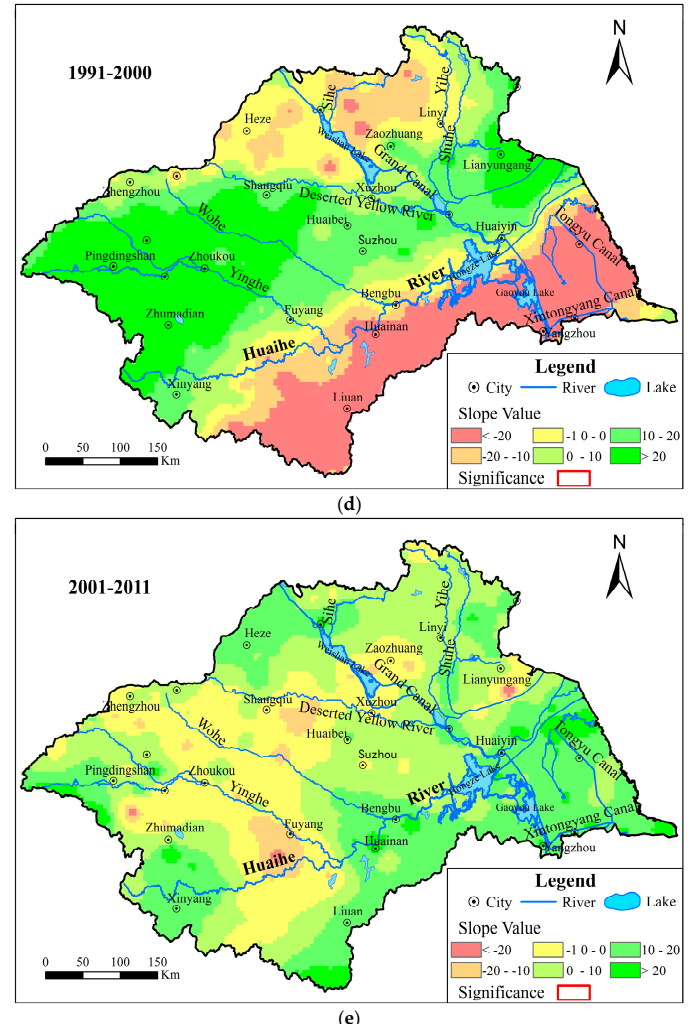

Figure 4. The spatial distribution of the tendency magnitude in the different decadal precipitation ((a) from 1961 to 1970; (b) from 1971 to 1980; (c) from 1981 to 1990; (d) from 1991 to 2000 and (e) from 2001 to 2011).
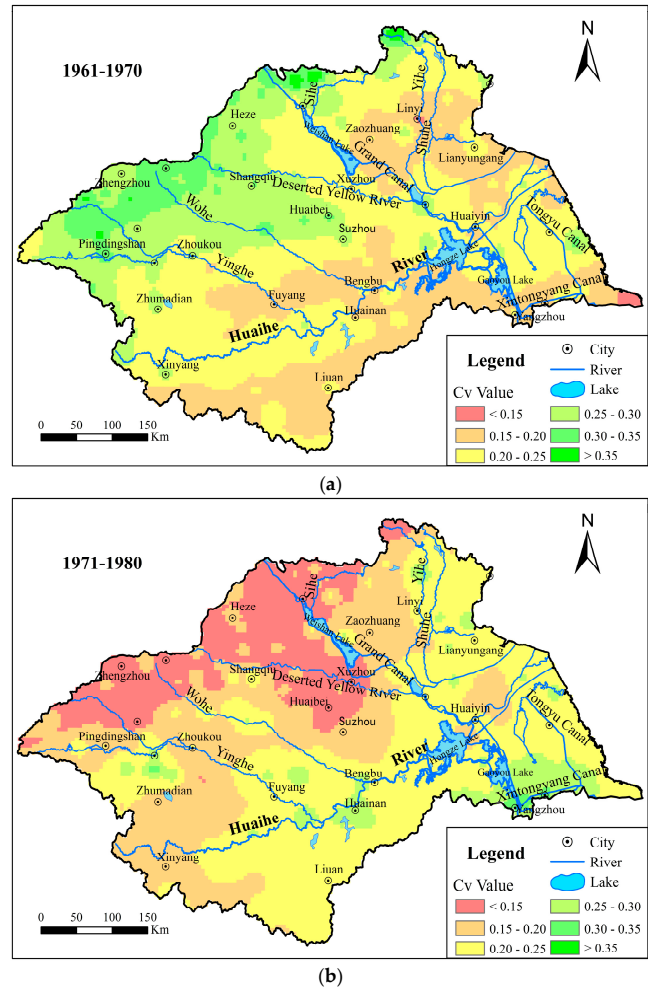

Figure 5. Cont. 

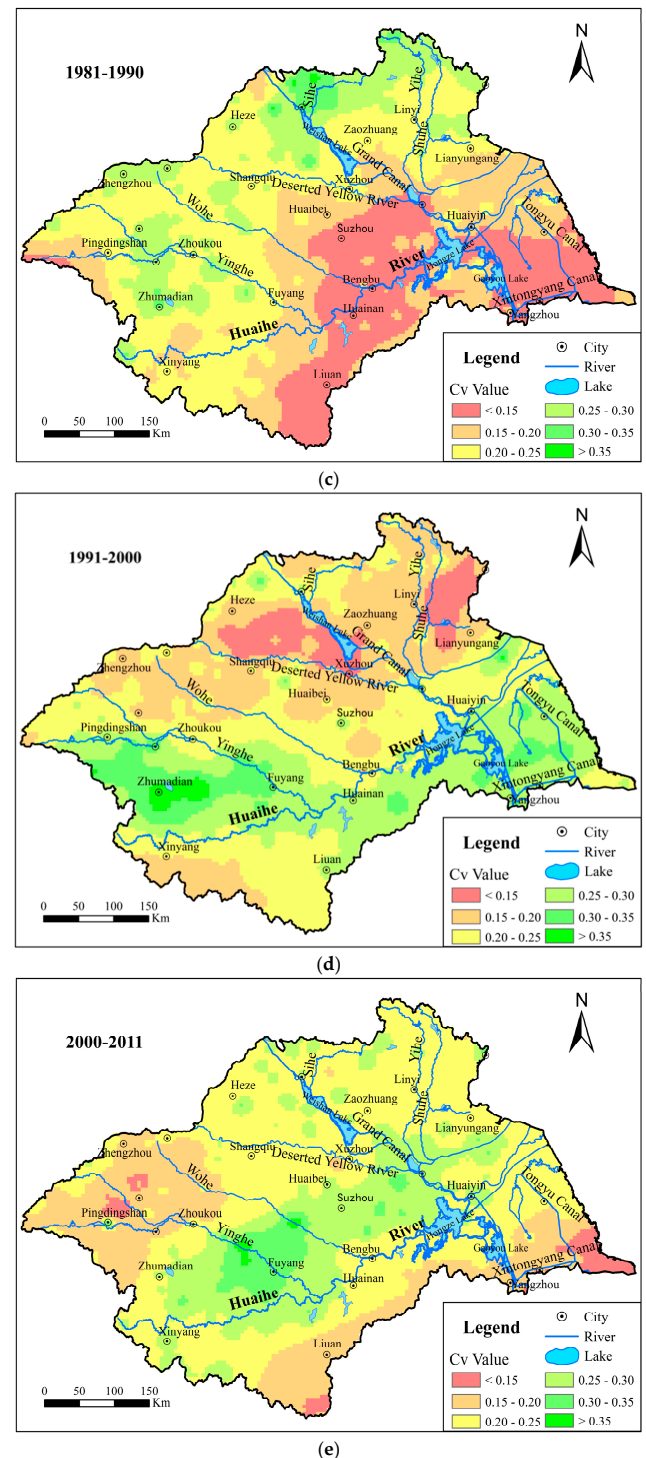

Figure 5. The spatial distribution of randomicity in the different decadal precipitation ((a) from 1961 to 1970; (b) from 1971 to 1980; (c) from 1981 to 1990; (d) from 1991 to 2000; (e) from 2001 to 2011).

\section{Discussion}

Based on the analysis of annual precipitation variability across the Huaihe River basin, we found the spatial and temporal dynamic characteristics changes, including the trends, the randomicity, abrupt change, and the periodicity. Different methods were adopted to derive these characteristic changes.

\subsection{Trends of the Precipitation}

Our results were consistent with scholars' findings but was different from others' [41,52-56]. The difference was derived from their various study area's boundaries. Most studies suggested that the Huaihe River basin did not include the Shandong peninsula, while others thought the opposite. The difference possibly stemmed from the fact that our study area did not include the Shandong Peninsula. Additionally, precipitation changes in China were mainly caused by the East Asian Monsoons and the precipitation pattern in China may change due to a reduction in the summer monsoon cycle [57]. The weakening of summer and winter monsoon contributed to increasing precipitation over Southeastern China $[57,58]$. However, there as a weakening relationship between East Asian winter monsoon and ENSO after mid-1970s [59]. The precipitation amount presented an advanced tendency 
after 1990s and increased obviously after $2000[52,60]$. Therefore, the summer and winter monsoon variations, especially around the mid-1970s, may be a possible factor for the precipitation changes in the Huaihe River basin.

\subsection{Randomicity of Precipitation}

Our results were similar to existing research findings [53,61]. The monsoon climate contributed to the uneven distribution of annual rainfall [61]. The annual rainfall uneven distribution also reflected that the Huaihe River basin was the climate transition zone (between $32^{\circ} 30^{\prime} \mathrm{N} \sim 33^{\circ} 55^{\prime} \mathrm{N}$ and $104^{\circ} 31^{\prime} \mathrm{E} \sim 120^{\circ} 25^{\prime} \mathrm{E}$ ) (Figure 1). The Huaihe River is known as the transitional river in China [54]. It is the important north-south geographical demarcation boundary and a climate transition zone in China: while the south of the river is subject to a warm, humid temperates and the north is a subtropical, semi-arid climate $[28,62,63]$. The climate of the basin is mainly a warm, temperate monsoon and sub-humid climate. The annual rainfall heterogeneity is not only related to the latitude, but also to the typical physiognomy of the Huaihe River basin [64]. The rainfall evenness could be affected by other factors (e.g., temperature, topography, atmospheric circulation) and these attribution analyses might be effective targets for the future.

\subsection{Abrupt Change of Precipitation}

Our outcomes are close to the results obtained by Yang, Lu, and Wang [33,52,65]. In 1965 and 2002 abrupt changes occurred [66], this was consistent with our findings. In addition, the results were almost identical with the previous studies of the heavy droughts that occurred in 2001 and $2002[67,68]$. The anomalous northeast cold vortex could lead to the abrupt changes of rainfall [69]. The rainfall abrupt change points were similar with the anomalous occurrence time in our study. In general, the abrupt changes mainly occurred in 1970s and after the 1990s, which was close to the results detected by $\mathrm{Lu}$ and Wang [52,70]. However, the strong rainfall occurred in 2003, 2005, and 2007 [71]. The Pettitt test did not capture these abrupt change points in our study, since the data used in our study were yearly rainfall rather than the seasonal data. Additionally, there are many reservoirs in the basin, and the rainfall abrupt changes may be controlled by the distribution of these reservoirs.

\subsection{Periodicity of Precipitation}

The study showed that there were about 5-year, 10-year, 15-year, and 30-year cycles in the Huaihe River [72]. This was close to our findings. However, due to the difference of time series of rainfall data used, the 30-year cycle does not exist in our study. However, the other studies obtained 7-9 years as the major cycle and two years as the second cycle [66], which was different from our findings. WANG used the annual day and night rainfall as the basic data to study day/night precipitation cycle change, respectively [66]. Otherwise, we used the annual rainfall to get the cycle period rather than the only day or night rainfall. Another study demonstrated that the Yangtze-Huaihe meiyu period were 6-7 year and quasi-20-year periodical oscillations [73], which are due to the same reasons as above.

The Huaihe River basin is the climate transition zone between the north subtropical zone and the south extratropical zone of China [74]. Precipitation in this watershed is influenced by the variation of the transition zone position and ENSO [74,75]. There is an evident correlation between ENOS events and the abnormity of rainfall in the Huaihe River [76]. Some studies deemed that the rainfall periodicity was 20-25 year, and there was a positive correlation between summer precipitation and solar activities in the Huaihe River.

\subsection{Advice for Management Implications in a Basin}

Rainfall is the primary water source in the Huaihe River basin. According to the above analysis, the change of rainfall intensity, quantity, and pattern could cause the extreme events, such as drought and flood [77]. A shift in the storm track makes some regions wetter and the nearby-regions drier [78]. 
Thus, the spatio-temporal variability of rain across the watershed affects the flood control planning and comprehensive management. The precipitation increased significantly and changed unevenly remarkably in the Guohe River basin. Floods may be more likely to occur and we should strengthen the control measures and formulate the corresponding water resources utilization policy in the basin.

\subsection{Future Challenges}

Latitude, atmospheric circulation, sea-land distribution, ocean current, and topography are the main factors that affect the climate change. Local and regional variations in the feature of rainfall depend on the variability patterns of atmospheric circulation. Human activities, surface evaporation density, and latent energy also affect the precipitation changes [78]. However, we have not discussed and quantified the specific factors (i.e., temperatures, evaporations, land use changes and human activities) that are controlling the trends of rainfall. In the coming months, combined with the climate change, land use, and water conservancy facilities, our investigation needs to determine the factors that affect the dynamic changes of rain across the basin. Meanwhile, we could use the multi-factors regression analysis to obtain the primary and secondary factors. We could also study the data extrapolated in other watersheds to confirm the scientific merit of the study. Some scholars and researchers may worry about the accuracy and precision of extrapolation, so they may not have included that in their research. Indeed, it is a limitation. Thus, we could study the data extrapolated in other watersheds to confirm the scientific merit of the study. Additionally, we could use remote sensing data or more reference materials to prove the accuracy of the extrapolated data.

\section{Conclusions}

In this study, the precipitation series were used to detect the spatial distribution of temporal variation characteristics for the period 1961 to 2011 in the Huaihe River basin. Although the trend changes are not significant, the precipitation varied markedly. Its spatial distribution characteristics presented the evident difference as well. The entire basin was dominated by the slight increasing trends of inter-annual and inter-decadal precipitation, especially in the upper and middle reaches of the Huaihe River. But for the inter-annual rainfall, the change trend did not present at $95 \%$ confidence level in most of basin. For the inter-decadal, all trend changes are insignificant. The abrupt points were various in different periods. According to the proportion of abrupt area in the entire basin, we obtained nine chiefly abrupt points and three principal periods. The $C v$ value indicated that the spatial distributions of precipitation were heterogeneous and the randomicity were all of moderate variability.

Most previous studies concentrated on the trend, periodicity, and abrupt change of precipitation based on point data of a single meteorological station. However, our study extrapolated the single data across the watershed grid data. We obtained the rain variability characteristics from four sections: the trend, the abrupt change, the periodicity, and the randomicity. Our study could add needed value to the scientific community, especially to the basin where there is a lack of scientific literature to document. Meanwhile, our results could provide the scientific support for water resources management in river basins.

Acknowledgments: The authors extend sincere thanks for the supports of the Representative Achievements and Cultivation Project of State Key Laboratory of Simulation and Regulation of Water Cycle in River Basin (No. 2016CG02) and the National Key Research and Development Project (No. 2016YFA0601503).

Author Contributions: Z.-L.Y. completed the statistical analysis and wrote the paper; D.-H.Y. provided the writing ideas and supervised the study; G.-H.N. guided the writing and finalized the paper; P.D. was responsible for study designing and modifying the language; D.-M.Y. was responsible for data processing and diagraming; T.-L.Q. took charge of diagraming and data analysis; S.-Y.C., B.-S.W. and M.-J.Y. (in the order of initial letter in surnames) have equal contributions, mainly in charge of literature retrieval, data collection and paper translation.

Conflicts of Interest: The authors declares that there is no conflict of interests regarding the publication of this paper. 


\section{References}

1. Limsakul, A.; Singhruck, P. Long-term trends and variability of total and extreme precipitation in Thailand. Atmos. Res. 2016, 169, 301-317. [CrossRef]

2. Oguntunde, P.G.; Abiodun, B.J.; Lischeid, G. Precipitation trends in Nigeria, 1901-2000. J. Hydrol. 2011, 411, 207-218. [CrossRef]

3. Sayemuzzaman, M.; Jha, M.K. Seasonal and annual precipitation time series trend analysis in North Carolina, United States. Atmos. Res. 2014, 137, 183-194. [CrossRef]

4. Wang, X.; Cui, G.; Wu, F.; Li, C.H. Analysis of temporal-spatial precipitation variations during the crop growth period in the Lancang River basin, southwestern China. Ecol. Eng. 2015, 76, 47-56. [CrossRef]

5. Xia, J.; She, D.X.; Zhang, Y.Y.; Du, H. Spatio-temporal trend and statistical distribution of extreme precipitation events in Huaihe River Basin during 1960-2009. J. Geogr. Sci. 2012, 22, 195-208. [CrossRef]

6. Chang, H.; Kwon, W.-T. Spatial variations of summer precipitation trends in South Korea, 1973-2005. Environ. Res. Lett. 2007, 2, 45012-45019. [CrossRef]

7. Chatterjee, S.; Khan, A.; Akbari, H.; Wang, Y.P. Monotonic trends in spatio-temporal distribution and concentration of monsoon precipitation (1901-2002), West Bengal, India. Atmos. Res. 2016, 182, 54-75. [CrossRef]

8. Irannezhad, M.; Marttila, H.; Chen, D.; Kløve, B. Century-long variability and trends in daily precipitation characteristics at three Finnish stations. Adv. Clim. Chang. Res. 2016, 7, 54-59. [CrossRef]

9. Zhao, C.Y.; Wang, Y.; Zhou, X.Y.; Cui, Y.; Liu, Y.L.; Shi, D.M.; Yu, H.M.; Liu, Y.Y. Changes in climatic factors and extreme climate events in Northeast China during 1961-2010. Adv. Clim. Chang. Res. 2013, 4, 92-102.

10. Tabari, H.; Abghari, H.; Hosseinzadeh Talaee, P. Temporal trends and spatial characteristics of drought and precipitation in arid and semiarid regions of Iran. Hydrol. Process. 2012, 26, 3351-3361. [CrossRef]

11. Zhang, W.; Pan, S.M.; Cao, L.G.; Cai, X.; Zhang, K.X.; Xu, Y.H.; Xu, W. Changes in extreme climate events in eastern China during 1960-2013: A case study of the Huaihe River Basin. Quat. Int. 2015, 380, $22-34$. [CrossRef]

12. Chen, Y.N.; Xu, C.C.; Hao, X.M.; Ye, Z.X. Fifty-year climate change and its effect on annual runoff in the Tarim River Basin, China. Quat. Int. 2009, 208, 53-61.

13. Tabari, H.; Talaee, P.H. Temporal variability of precipitation over Iran: 1966-2005. J. Hydrol. 2011, 396, 313-320. [CrossRef]

14. Tian, Q.; Prange, M.; Merkel, U. Precipitation and temperature changes in the major Chinese river basins during 1957-2013 and links to sea surface temperature. J. Hydrol. 2016, 536, 208-221. [CrossRef]

15. Fu, G.B.; Yu, J.J.; Yu, X.B.; Ouyang, R.L.; Zhang, Y.C.; Wang, P.; Liu, W.B.; Min, L.L. Temporal variation of extreme precipitation events in China, 1961-2009. J. Hydrol. 2013, 487, 48-59. [CrossRef]

16. Liu, Q.; Yang, Z.; Cui, B. Spatial and temporal variability of annual precipitation during 1961-2006 in Yellow River Basin, China. J. Hydrol. 2008, 361, 330-338. [CrossRef]

17. Liu, Y.; Li, X.; Zhang, Q.; Guo, Y.F.; Gao, G.; Wang, J.P. Simulation of regional temperature and precipitation in the past 50 years and the next 30 years over China. Quat. Int. 2010, 212, 57-63. [CrossRef]

18. Liu, H.Y.; Gao, Q. Contribution rate of driving factors on the rainfall-sediment relationship of Longhe River watershed in the Three Gorges Reservoir region. Sci. Soil Water Conserv. 2015, 13, 1-8.

19. Portmann, R.W.; Solomon, S.; Hegerl, G.C. Spatial and seasonal patterns in climate change, temperatures, and precipitation across the United States. Proc. Natl. Acad. Sci. USA 2009, 106, 7324-7329. [CrossRef] [PubMed]

20. Keggenhoff, I.; Elizbarashvili, M.; Amiri-Farahani, A.; King, L. Trends in daily temperature and precipitation extremes over Georgia, 1971-2010. Weather Clim. Extrem. 2014, 4, 75-85. [CrossRef]

21. Beecham, S.; Chowdhury, R.K. Temporal characteristics and variability of point precipitation: A statistical and wavelet analysis. Int. J. Climatol. 2010, 30, 458-473.

22. Sang, Y.F.; Singh, V.P.; Gong, T.; Xu, K.; Sun, F.; Liu, C.; Liu, W.; Chen, R. Precipitation variability and response to changing climatic condition in the Yarlung Tsangpo River basin, China. J. Geophys. Res. Atmos. 2016, 121, 8820-8831. [CrossRef]

23. Wang, R.; Li, C. Spatiotemporal analysis of precipitation trends during 1961-2010 in Hubei province, central China. Theor. Appl. Clim. 2016, 124, 385-399. [CrossRef] 
24. Karpouzos, D.K.; Kavalieratou, S.; Babajimopoulos, C. Trend analysis of precipitation data in Pieria Region (Greece). Eur. Water 2010, 30, 31-40.

25. Shi, P.; Rui, X.F. Comparison and improvement of spatial rainfall interpolation methods. J. Hohai Univ. (Nat. Sci.) 2005, 33, 361-365. (In Chinese)

26. Mohamed, A.S. Reliabilty Estimation of Rainfall-Runoff Models; State University of New York: New York, NY, USA, 1999.

27. Shi, P.; Ma, X.X.; Chen, X.; Qu, S.M.; Zhang, Z.C. Analysis of variation trends in precipitation in an upstream catchment of Huai River. Math. Probl. Eng. 2013, 2013, 1262-1268. [CrossRef]

28. Zhou, Y.K.; Wang, L.C.; Peng, X.Y.; Zhang, J. Chaotic dynamics of the flood series in the Huaihe river basin. J. Hydrol. 2002, 258, 100-110. [CrossRef]

29. Song, X.S.; Yan, D.H.; Wang, Y.H.; Wang, Y. Analysis on the evolution of drought and flood class in the east-central Huang-Huai-Hai plain over the last 540 years basing on Markov model. J. Hydrol. Eng. 2013, 12, 1425-1432. (In Chinese)

30. Yang, Z.Y.; Yuan, Z.; Yan, D.H.; Weng, B. Study of spatial and temporal distribution and multiple characteristics of drought and flood in Huang-Huai-Hai River basin. Adv. Water Sci. 2013, 24, 617-625. (In Chinese)

31. Croley, T.E., II; Hartmann, H.C. Resolving Thiessen polygons. J. Hydrol. 1985, 76, 363-379. [CrossRef]

32. China Meteorological Data Service Center (CMDC). Available online: http://data.cma.cn/data/cdcdetail/ dataCode/SURF_CLI_CHN_MUL_DAY.html (accessed on 20 March 2012).

33. Yang, M.M.; Zhong, P.A.; Wei, P. Study on precipitation evolution rule of Huaihe River Basin in main flood period. Water Resour. Power 2012, 30, 37-40.

34. Wei, F.Y. Xiandai Qiuhou Tongji Zhenduan Yu Yuce Jishu; China Meteorological Press: Beijing, China, 2007; pp. 99-104.

35. Li, M.; Xia, J.; Chen, S.M.; Meng, D.J. Wavelet analysis on annual precipitation around 300 Years in Beijing Area. J. Nat. Resour. 2011, 6, 1001-1011. (In Chinese)

36. Teoh, W.L.; Khoo, M.B.C.; Castagliola, P.; Yeong, W.C.; Teh, S.Y. Run-sum control charts for monitoring the coefficient of variation. Eur. J. Oper. Res. 2017, 257, 144-158. [CrossRef]

37. Aerts, S.; Haesbroeck, G.; Ruwet, C. Multivariate coefficients of variation: Comparison and influence functions. J. Multivar. Anal. 2015, 142, 183-198. [CrossRef]

38. Dong, X.G.; Gu, W.Z.; Meng, X.X.; Liu, H.B. Change features of precipitation events in Shandong Province from 1961 to 2010. Acta Geogr. Sin. 2014, 69, 661-671. (In Chinese) [CrossRef]

39. Xia, J.; Ou, C.P.; Huang, G.H.; Wang, Z.G. The analysis of Haihe River Basin hydro-meteorological spatio-temporal variability based on GIS and information difference measure. J. Nat. Resour. 2007, 22, 409-415. (In Chinese)

40. Wang, X.J.; He, M.R.; Shang, M.T. Evolution law of precipitation in Yulin. J. Arid Land Resour. Environ. 2011, 25, 103-108. (In Chinese)

41. Yan, D.H.; Han, D.M.; Wang, G.; Yuan, Y.; Hu, Y.; Fang, H.Y. The evolution analysis of flood and drought in Huai River Basin of China based on monthly precipitation characteristics. Nat. Hazards 2014, 73, 849-858. [CrossRef]

42. Jin, Y.; Yan, A.; Jiang, P.A.; Wang, Z.; Wang, X.J. Spatial variability of filed soil water in Manas River Basin. Xinjiang Agric. Sci. 2013, 50, 1554-1559. (In Chinese)

43. Pettitt, A.N. A non-parametric approach to the change-point problem. J. R. Stat. Soc. 1979, 28, $126-135$. [CrossRef]

44. Zhang, Y.M.; Tian, Y.; Lei, X.H.; Song, W.Z.; Jiang, Y.Z. Change characteristics of water resources in Sanchahe Upstream over past 50 years. J. China Hydrol. 2016, 36, 79-84.

45. Yi, H.; Shu, H. The improvement of the Morlet wavelet for multi-period analysis of climate data. Comptes Rendus Geosci. 2012, 344, 483-497. [CrossRef]

46. Hermida, L.; López, L.; Merino, A.; Berthet, C.; Gercía-Ortega, E.; Sánchez, J.L.; Dessens, J. Hailfall in southwest France: Relationship with precipitation, trends and wavelet analysis. Atmos. Res. 2015, 156, 174-188. [CrossRef]

47. Zhang, S.Y.; Wang, J.H.; Zhai, J.Q.; Li, H.H.; Zhao, Y.; Wang, Q.M.; Zhang, W. Characteristics analysis of time serial of rainfall in the Northern part of Haihe River Basin from 1956 to 2012. South-to-North Water Transf. Water Sci. Technol. 2016, 14, 36-42. (In Chinese) 
48. Domingues, M.O.; Mendes, O.; da Costa, A.M. On wavelet techniques in atmospheric sciences. Adv. Space Res. 2005, 35, 831-842. [CrossRef]

49. Li, D.; Guo, Z. Some aspects of ecological modeling developments in China. Ecol. Model. 2000, 132, 3-10. [CrossRef]

50. Kovács, J.; Hatvani, I.G.; Korponai, J.; Kovács, I.S. Morlet wavelet and autocorrelation analysis of long-term data series of the Kis-Balaton water protection system (KBWPS). Ecol. Eng. 2010, 36, 1469-1477. [CrossRef]

51. Labat, D. Recent advances in wavelet analyses: Part 1. A review of concepts. J. Hydrol. 2005, 314, $275-288$. [CrossRef]

52. Lu, Z.G.; Zhang, X.H.; Huo, J.L.; Wang, K.Q.; Xie, X.P. The evolution characteristics of the extreme precipitation in Huaihe river basin during 1960-2008. J. Meteorol. Sci. 2011, 31, 74-80.

53. Xing, W.Q.; Wang, W.Q.; Wu, Y.Q.; An, G.Y. Change properties of precipitation concentration in Huaihe River Basin. Water Resour. Power 2011, 29, 1-5.

54. Zhang, D.D.; Yan, D.H.; Wang, Y.C.; Lu, F.; Wu, D. Changes in extreme precipitation in the Huang-Huai-Hai River basin of China during 1960-2010. Theor. Appl. Clim. 2015, 120, 195-209. [CrossRef]

55. Zhou, L.G.; Dai, S.B. Spatial and temporal variation characteristics of heavy rainfall in the Huaihe River Basin in recent 60 years. South-to-North Water Transf. Water Sci. Technol. 2015, 5, 847-852. (In Chinese)

56. Yuan, Z.; Yang, Z.Y.; Zheng, X.D.; Yuan, Y. Spatial and temporal variations of precipitation in Huaihe River Basin in resent 50 years. South-to-North Water Transf. Water Sci. Technol. 2012, 10, 98-103. (In Chinese)

57. Xu, M.; Chang, C.P.; Fu, C.; Qi, Y.; Robock, A.; Robinson, D.; Zhang, H.M. Steady decline of East Asian monsoon winds, 1969-2000: Evidence from direct ground measurements of wind speed. J. Geophys. Res. Atmos. 2006, 111, 906-910. [CrossRef]

58. Zhou, L.T. Impact of East Asian winter monsoon on precipitation over southeastern China and its dynamical process. Int. J. Clim. 2011, 31, 677-686. [CrossRef]

59. Wang, H.J.; He, S.P. Weakening relationship between East Asian winter monsoon and ENSO after mid-1970s. Chin. Sci. Bull. 2012, 57, 3535-3540. [CrossRef]

60. Wang, Y.; Cao, M.K.; Tao, B.; Li, K.R. The characteristics of spatio-temporal patterns in precipitation in China under the background of global climate change. Geogr. Res. 2006, 25, 1031-1040. (In Chinese)

61. Gu, W.L.; Wang, J.J.; Zhu, Y.Y.; Sun, C.R. Annual distribution of precipitation over the Huaihe River Basin. Resour. Environ. Yangtze Basin 2010, 19, 429-434. (In Chinese)

62. Wang, K.; Chu, D.; Yang, Z. Flood control and management for the transitional Huaihe River in China. Procedia Eng. 2016, 154, 703-709.

63. Wang, J.; Liu, G.J.; Lu, L.L.; Zhang, J.M.; Liu, H.Q. Geochemical normalization and assessment of heavy metals $(\mathrm{Cu}, \mathrm{Pb}, \mathrm{Zn}$, and $\mathrm{Ni})$ in sediments from the Huaihe River, Anhui, China. Catena 2015, 129, 30-38. [CrossRef]

64. Ye, J.Y.; Huang, Y.; Zhang, C.L.; Li, Z.J. Characteristics of precipitation days and intensity over the Huaihe River basin in flood season during recent 50 years. J. Lake Sci. 2013, 25, 583-592. (In Chinese)

65. Wang, S.; Tian, H.; Ding, X.J.; Xie, W.S.; Tao, Y. Analysis of extreme precipitation events in rainy season over Huaihe River Basin from 1961 to 2008. Meteorol. Sci. Technol. 2012, 40, 87-91. (In Chinese)

66. Wang, S.; Xie, W.S.; Tang, W.A.; Tao, Y.; Ding, X. Change characteristics of day and night precipitation in Huaihe River Basin in 1961-2009. Chin. J. Ecol. 2011, 30, 2881-2887. (In Chinese)

67. Dai, X.G.; Wang, P.; Chou, J.F. Multi-scale characteristics of precipitation in rainy season and summer monsoon decadal decay in North China. Chin. Sci. Bull. 2003, 48, 2483-2487. (In Chinese) [CrossRef]

68. Wang, J.T.; Liang, S.X.; Yu, H. Analysis of water potential in Huaihe River Basin during 2000 to 2009. China Flood Drought Manag. 2011, 21, 21-24. (In Chinese)

69. Li, C.; Han, G.R.; Sun, Y. Anomalous features of Northeast cold vortex in late 50 a and its correlation with rainfall in Huaihe river valley. J. Meteorol. Sci. 2015, 35, 216-222. (In Chinese) [CrossRef]

70. Wang, S.; Tian, H.; Ding, X.J.; Xie, W.S.; Tao, Y. Climate characteristics of precipitation and phenomenon of drought-flood abrupt alternation during main floods season in Huaihe River Basin. Chin. J. Agrometeorol. 2009, 30, 31-34. (In Chinese)

71. Gao, C.; Jiang, T.; Zhai, J.Q. Analysis and precipitation of climate in the Huaihe River Basin. Chin. J. Agrometeorol. 2012, 33, 8-17. (In Chinese) [CrossRef] 
72. Wang, J.C.; Guo, J.X.; Xu, J.; Li, F. Multi-time scales change characteristics and relationship of meteorological variables in the upper and middle regions of the Huaihe River Basin in recent 55 years. Sci. Geogr. Sin. 2017, 37, 611-619. [CrossRef]

73. Hu, Y.M.; Ding, Y.H.; Liao, F. A classification of the precipitation patterns during the Yangtze-Huaihe meiyu period for recent 52 years. Acta Meteorol. Sin. 2010, 68, 235-247. (In Chinese)

74. Liu, F.H.; Chen, X.; Chen, X.W.; Song, S. Relations hip between temperature change in climate boundary and summer precipitation over the Huaihe River basin. Clim. Environ. Res. 2010, 15, 169-178. (In Chinese)

75. Wang, Y.; Zhang, Q.; Zhang, S.; Chen, X.H. Spatial and temporal characteristics of precipitation in the Huaihe River Basin and its response to ENSO events. Sci. Geogr. Sin. 2016, 36, 128-134. [CrossRef]

76. Xin, Z.B.; Xie, Z.R. The impact of ENSO events on Huaihe River Basin's precipitation. Sci. Meteorol. Sin. 2005, 25, 346-354.

77. Shi, P.; Qiao, X.Y.; Chen, X.; Zhou, M.; Qu, X.X.; Zhang, Z.C. Spatial distribution and temporal trends in daily and monthly precipitation concentration indices in the upper reaches of the Huai River, China. Stoch. Environ. Res. Risk Assess. 2014, 28, 201-212. [CrossRef]

78. Trenberth, K.E. Changes in precipitation with climate change. Clim. Res. 2011, 47, 123-138. [CrossRef]

(C) 2017 by the authors. Licensee MDPI, Basel, Switzerland. This article is an open access article distributed under the terms and conditions of the Creative Commons Attribution (CC BY) license (http:/ / creativecommons.org/licenses/by/4.0/). 